\title{
Screening of Blood Donors for Transfusion Transmitted Infections in Tertiary Care Hospital of Faisalabad
}

\author{
Sarwat Jahan, Saira Mushtaq, Farah Amir Ali
}

\begin{abstract}
Background:Blood transfusion saves millions of lives worldwide each year and reduces morbidity but at the same time is a source for potentially life threatening transfusion transmissible infections (TTIs). These TTIs are a threat to blood safety. Sensitive screening with advanced technologies reduces the risk of TTIs, but it still remains a major concern. Objective of this study was to determine the frequencies of various ABO blood groups and to screen the TTIs like Hepatitis B (HBV), Hepatitis C (HCV), Human Immunodeficiency Virus (HIV), Syphilis and Malaria among voluntary and replacement blood donors of Faisalabad.

Methodology:This cross sectional study was conducted at Aziz Fatimah Hospital Faisalabad, from July 2018 to November 2018. After taking informed consent all replacement and voluntary blood donors were screened for HCV, HBV, HIV, syphilis and malaria.

Results:During 5 months of study period, total 1942 patients, of age ranged 18-40 years, were screened for TTIs. All blood donors were male; no female came to donate blood during this duration. Highest percentage of study population were blood group B (36.9\%), followed by blood group O (28.1), A (22.2\%), and AB (9.2\%) respectively. Frequencies and percentages of Rhesus blood groups exhibited the predominance of positive rhesus groups in the study population. Out of total donors, 78 (4\%) were infected with HCV, $30(1.5 \%)$ with HBV, $10(0.5 \%)$ with HIV, $19(1 \%)$ with syphilis and $3(0.20 \%)$ were seropositive for Malaria. Therefore, $140(7.2 \%)$ blood donors out of total were seropositive for various TTIs.

Conclusion:This study showed the seroprevalence of transfusion transmitted infections (TTIs) among the blood donors. Highest percentage of blood donors suffered from HCV, followed by HBV, syphilis, HIV and malaria.

Key Words: Transfusion transmitted infections, Human immunodeficiency virus, Hepatitis B virus, Hepatitis C virus, Syphilis, Malaria
\end{abstract}

\section{Introduction}

Blood donation is an intricate procedure comprising of collection, testing, preparing, and storing of blood and blood components. ${ }^{1}$ Blood donors can be of two types; voluntary blood donor and replacement blood donors. ${ }^{2}$ Blood donated by these donors is then utilized in carrying out blood transfusions. In Pakistan, approximately, greater than 1.5 million units of blood are collected each year. ${ }^{2}$ The majority of these donors are replacement donors, mostly family members or friends of the patients with the intention to help in emergency situation. ${ }^{3}$ Blood transfusion is a methodology orchestrated routinely in tertiary hospitals as an indispensible technology. However, it

\section{Sarwat Jahan}

Assistant Professor

Aziz Fatimah Medical and Dental College (AFMDC),

Faisalabad,

Dr Saira Mushtaq

Assistant Professor

Aziz Fatimah Medical and Dental College (AFM\&DC),

Faisalabad,

Dr Farah Amir Ali

Professor

Aziz Fatimah Medical and Dental College (AFMDC),

Faisalabad,

Correspondence

Dr. Sarwat Jahan,

Email:drsarwat78@hotmail.com can result in immediate or late complications. ${ }^{2}$ These complications have resulted in substantial disagreeable health outcomes leading to an increased frequency of morbidity and mortality. Therefore transfusion-related safety is of utmost importance and cannot be overemphasized. ${ }^{3}$ To ensure the safe blood for transfusion, a blend of cautious donor selection and sensitive screening with advanced technologies and viral inactivation procedures were used. ${ }^{2}$ These protective measures though have dramatically reduced the risk of transfusion transmissible infections (TTIs), but it still remains a major concern. ${ }^{1,2}$ Blood transfusion continues to be a major source of viral, bacterial and parasitic infections. ${ }^{2,4}$ Blood donation during window period might transmit diseases to the recipients and prevalence of these asymptomatic carriers poses a serious challenge to blood safety. ${ }^{1}$ Hepatitis $\mathrm{B}$ and $\mathrm{C}$ are most common blood borne infections due to use of unsafe injections and unhygienic instruments. Blood for donation are commonly screened for these infections. However latest studies have reported increased prevalence of other transfusion related infections in addition to $\mathrm{HBV}$ and $\mathrm{HCV}$, especially Acquired Immunodeficiency Syndrome (AIDS) caused by Human Immunodeficiency Viruses (HIV), Syphilis caused by spirochaete, Treponema 
pallidum and Malaria. ${ }^{4}$ Transfusion-transmitted malaria (TTM) is most frequently caused by plasmodium, falciparum and malariae. In the recipient's bloodstream it triggers the development of high risk complications leading to a lethal outcome especially in individuals with no previous exposure to malaria or in immunocompromised patients. ${ }^{5}$ Transfusion-transmitted syphilis (TTS) is also a serious public issue in developing countries. According to World Health Organization (WHO), among 12 million new cases of syphilis, more than $90 \%$ cases are reported in developing countries, each year. ${ }^{6} \mathrm{WHO}$ recommends screening of all donated blood for syphilis and malaria, but it is challenging for many countries with poor resources. Blood banks in lowincome countries do not screen donated blood for syphilis, as it is unaffordable for many patients. ${ }^{7}$ Along with the screening of the hepatitis and HIV there is emergent need to screen for syphilis and malaria. Morbidity and mortality from the transfusion of infected blood have inculcated more alarming condition, not only for the recipients but also for their families and communities worldwide. Risk for TTIs needs to be taken into account in order to enhance the safety of the blood donation by means of appropriate screening of blood. Ensuring sufficient supplies of safe blood and prevention of transmission of transfusion-transmissible infections are major public health responsibilities of every government and health professionals.

\section{AIM}

This study was designed to screened blood for transfusion- transmitted infections (TTI) like HBV, HCV and HIV, syphilis and malaria among voluntary and replacement blood donors of Faisalabad and secondarily to determine the frequencies of various $\mathrm{ABO}$ blood groups among them.

\section{Methodology}

This cross sectional study was conducted at Aziz Fatimah Hospital Faisalabad from July 2018 to November 2018. Ethical approval was taken from ethical committee of the hospital prior to commencement of the study. All replacement and voluntary blood donors, who came to the hospital for blood donation in this duration, were included in study. All professional blood donors and addict persons were excluded. Every unit of the collected blood for donation were screened for transfusion transmitted infections including hepatitis B surface antigen ( $\mathrm{HBs} \mathrm{Ag}$ ), HCV, HIV, syphilis, and malaria. Prior to screening, informed consent was taken from each blood donor. Screening of blood units was done by enzyme-linked immunosorbent assay (ELISA) method for HIV and hepatitis B and C. HIV testing was done using fourth generation ELISA kits. Syphilis was tested by latex agglutination assay and malaria was tested using slide method and by rapid immunechromatographic assay. Any sample found reactive, was retested for confirmation. Seropositive units were discarded to avoid contamination. The criteria for validity of ELISA tests given by the manufactures were considered. Cut off value for reporting positive results was calculated as per manufacturer's directions. All laboratory records were maintained by central data base of the hospital. For analysis data were retrieved and transported to SPSS version 22 for analysis. Frequencies and percentages for various blood groups, seropositive (reactive) and seronegative (non-reactive) tests for $\mathrm{HBsAg}, \mathrm{HCV}$, HIV, syphilis and malaria (TTIs) were obtained.

\section{RESULTS}

During 5 months duration of study, total 1942 patients came to hospital for blood donation and they were screened for TTIs. All blood donors were male; no female came to donate blood during this duration. Blood donors were of age range 18-40 years. Distribution of ABO blood groups is indicated in Figure.1. Among 1942 blood donors, 743(36.9\%) belonged to blood group B, 447 (22.2\%) belonged to blood group A, 567(28.1\%) were of blood group $\mathrm{O}$ and $185(9.2 \%)$ had blood group $\mathrm{AB}$. Highest percentage of study population were of blood group $\mathrm{B}$ followed by $\mathrm{O}, \mathrm{A}$ and $\mathrm{AB}$ respectively (Figure.1). Frequency and percentages of Rhesus blood groups were showing the predominance of positive rhesus groups i.e 1757 (90.4\%) in study population, while only $185(9.5 \%)$ of population was rhesus negative. data regarding seropositive and seronegative for various TTIs is presented in table1. Out of these donors $78(4 \%)$ were infected with HCV, 30 (1.5\%) with HBV, $10(0.5 \%)$ with HIV, 19 (1\%) with syphilis and $3(0.20 \%)$ were seropositive for Malaria (Table 1). Of total, 140 (7.2\%) blood donors were seropositive for various TTIs.

Table 1: Frequencies of Transfusion- Transmitted Infections (TTI)

$\mathrm{N}=1942$

\begin{tabular}{|l|c|c|}
\hline $\begin{array}{c}\text { Transfusion-Transmitted } \\
\text { Infections (TTI) }\end{array}$ & Reactive test & Non-reactive test \\
\cline { 2 - 3 } & $\mathbf{N ~ ( \% )}$ & $\mathbf{N}(\mathbf{\%})$ \\
\hline Hepatitis B (HBsAg) & $30(1.5)$ & $1912(98.5)$ \\
\hline Hepatitis C (anti-HCV) & $78(4)$ & $1864(96)$ \\
\hline HIV & $10(0.5)$ & $1932(99.5)$ \\
\hline Syphilis & $19(1)$ & $1923(99)$ \\
\hline Malaria & $3(0.20)$ & $1939(99.8)$ \\
\hline
\end{tabular}


Figure 1: Distribution of Blood groups among study population

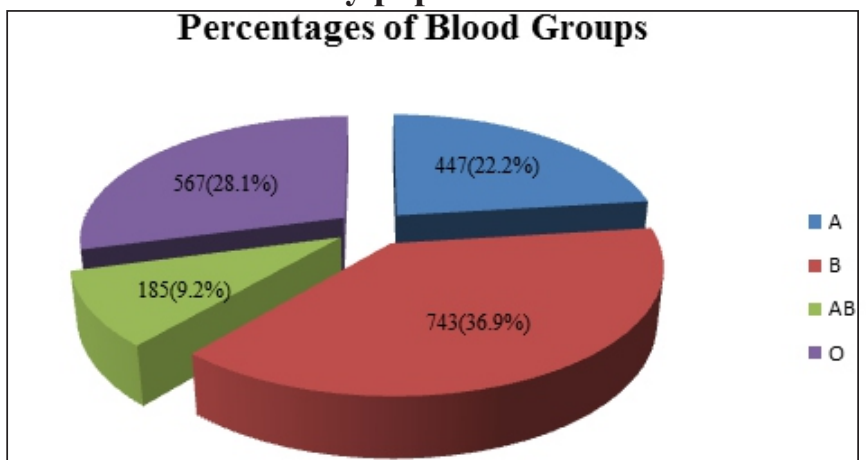

DISCUSSION

Although blood transfusion saves the lives of millions of people worldwide, the patients who undergo blood transfusion are at a potential high risk of transfusiontransmitted infections (TTIs). According to our study results, highest percentage of study population were blood group B ( $36.9 \%)$, followed by O (28.1\%), A $(22.2 \%)$, and $\mathrm{AB}(9.2 \%)$ respectively. Frequency and percentage of Rhesus blood groups showed the predominance of positive rhesus groups in the study population. 1757 (90.4\%) was rhesus positive, while only $185(9.5 \%)$ of population was rhesus negative. Similar trends are also reported by the previous studies conducted in Punjab. ${ }^{8,9}$ The prevalence of Hepatitis B virus (HBV) and Hepatitis $\mathrm{C}$ virus (HCV) in Pakistan is high $(2.5 \%$ and $25 \%)$ respectively. ${ }^{3,10}$ However latest studies have reported increased prevalence of other transfused related infections especially Human immunodeficiency viruses (HIV) and Syphilis., ${ }^{4,11,12}$ Commonly, the diagnosis of HBV, HCV, HIV and syphilis is based on the presence of their respective antigens or antibodies in blood. ${ }^{13}$ In this study, we evaluated the seroprevalence of different microbes including HBV,HCV,HIV, syphilis and malaria among 1942 blood donors from the laboratory of Faisalabad based hospital. All donors in our study were male of about 18-40 years of age group. A similar trend was seen in previous study conducted by Saghir et al. ${ }^{14,15}$ In this study, seroprevalence of HCV was highest (4\%), HBsAg $(1.5 \%)$ while that of syphilis was $(1 \%)$ which was seem to be high in comparison to frequency of HIV and malaria $(0.5 \%, 0.2 \%$ respectively) among blood donors over the study period of 5 months. Previous studies conducted in Rawalpindi Pakistan and neighbor country Iran, showed similar rising frequencies of HBV $2.45 \%$ and $2.3 \%$ respectively. ${ }^{15,16} 1.5 \%$ of the population of current study was infected with HBV. Similar figures were also reported by Arshad A et al, who found seropositivity of $\mathrm{HBV}$ in $1.8 \%$ in their studied population at Karachi. ${ }^{3}$ While study done in Sri Lanka has been reported significantly lower frequency of HBV (less than $2 \%$ )as compared to our findings and other studies reported from Pakistan. ${ }^{17}$ In our study, the frequency of $\mathrm{HCV}$ in the blood donors was also much higher (4\%) as compared to that reported by other researchers. I.7\% is reported by Arshad A et al from Karachi, Saghir et al $(0.79 \%)$ and by El-Hazmi MM et al $(0.4 \%){ }^{14,18}$ Our study showed high rate of HCV through blood transfusion in Faisalabad as compared to other regions of Pakistan. However our findings were lower than the previous studies conducted in Faisalabad which was evident for rising prevalence of $\mathrm{HCV}$ in Faisalabad than other regions of Punjab. Ahmed $\mathrm{N}$ etal reported prevalence of $16 \% \mathrm{HCV}$ patients among the blood donors visiting to Allied Hospital Faisalabad. ${ }^{19}$ Another study from Faisalabad also reported higher prevalence of $21.99 \%$ of $\mathrm{HCV}$ in general population. ${ }^{20}$ Different rates between current and previous studies can be justified by the fact that our study sample comprised of subjects visiting one private hospital of Faisalabad, whereas, previous reports included subjects visiting HCV screening camps and blood donors at the huge government sectors. Another review documented from Faisalabad in 2017 is also evident of rising prevalence of $\mathrm{HCV}$ in Punjab, which was $5.46 \%$, which is near to our study results and much higher than other regions of Pakistan specially Sindh. ${ }^{21}$ The percentage of HIV-positive blood donors in our study was comparatively higher $(0.5 \%)$ then the study done in Islamabad and Bahawalpur $(0 \%)^{15}$ and $0.04 \%$ of the HIV infections was reported from Karachi. ${ }^{3}$ However it showed slightly decreasing trend when compared with the results reported in different regions $(0.80 \%)$ in East Delhi, India ${ }^{3,15}$ and $(0.96 \%)$ in Nigeria. ${ }^{3,15,22}$ Other studies conducted by Attaullah S, Manzoor I etal. showed decreasing trend for HIV in Pakistan. ${ }^{4,23}$ Positive cases of syphilis in this study was $0.9 \%$ which showed rising trend as compared to $0.34 \%$ in study conducted by Saghir et al, $0.75 \%$ in study conducted by Chaudhary et a ${ }^{14,15}$ and 0.1 $\%$ in Port Harcourt, South-South, Nigeria. ${ }^{24}$ Another study was conducted in Islamabad had also reported a rising seroprevalence of syphilis $0.89 \%$ which was very nearer to our study results. ${ }^{24}$ Similar study conducted in Karachi was documented the higher prevalence of syphilis $(2 \%)$ than all the studies discussed above. ${ }^{4}$ Previous studies in India also showed very low prevalence as compared to our study. ${ }^{25}$ Thus, the frequency of syphilis observed in our study and other studies conducted in Pakistan was higher as compared to the other international studies ${ }^{25,26}$ Although, one limitation in our study is that evolution of syphilis could not be assessed clinically and only seropositive results 
could hallmark the underlying disease. Due to rising trend of Syphilis, HCV and HIV among blood donors in Pakistan, there is an urgent need for screening of donor's blood for TTIs to prevent the blood recipient from transmitted infections as much as possible. Such researches will play a key role to improve public health and awareness regarding transfusion transmitted infections and also used to control safety and quality of blood.

Conclusion

This study showed the seroprevalance of transfusion transmitted infections (TTIs) among the blood donors. Highest percentage of blood donors suffered from HCV, followed by HBV, syphilis, HIV and malaria. Blood group $\mathrm{B}$ was commonest and $\mathrm{AB}$ was least frequent among donors.

Conflict of interest: None

Funding: None

\section{References}

1.Blood donor selection. Guidelines on assessing donor suitability for blood donation. Annex 3. Geneva: World HealthOrganization;2012.

http://www.who.int/bloodsafety/voluntary_donation/bl ood_donor_selection_counselling/en/

2.Bhaumik P, Debnath K. Prevalence of Blood-Borne Viral Infections among Blood Donors of Tripura. Euroasian J Hepatogastroenterol. 2014;4(2):79-82.doi: 10.5005/jp-journals-10018-1106.

3.Arshad A, Borhany M, Anwar N, Naseer I, Ansari R, etal. Prevalence of transfusion transmissible in fections in blood donors of Pakistan. BMC Hematol. 2016; 16:27. eCollection 2016.

4.Attaullah S, Khan S, Khan J. Trend of transfusion transmitted infections frequency in blood donors: provide a road map for its prevention and control.J Transl Med. 2012;31;10:20. doi: 10.1186/1479-5876-10-20

5. Verra F, Angheben A, Martello E, Giorli G, Perandin F, Bisoffi Z. A systematic review of transfusion-transmitted malaria in non-endemic areas. Malar J.2018;16; 17(1):36. doi: 10.1186/s12936-018-2181-0.

6.Kaur G, Kaur P. Syphilis testing in blood donors: an update. Blood Transfus. 2015; 13(2):197-204. doi: 10.2450/2014.0146-14.

7.Owusu-Ofori AK, Parry CM, Bates I.Transfusion- transmitted Syphilis in Teaching Hospital, Ghana. Emerg Infect Dis. 2011;17(11):2080-2. doi:

10.3201/eid1711.110985

8.Kanwal S, Qureshi HJ, Aslam MS, Masood S. Frequency of $\mathrm{ABO}$ and $\mathrm{Rh}$ blood groups in students of Akhtar Saeed Medical and Dental College, Lahore. Pak J Physiol 2016;12(1):29-30.

9.Khan MU, Bashir MW, Rehman R, Kiani RA. Frequency of $\mathrm{ABO}$ and Rh (D) Blood Groups Among Blood Donors in Lahore, Pakistan. IJ ABBR 2014; 29 (3):597-600.

10.Memon FA, Ujjan ID, Memon AI, Shaikh AR, Rao AR,NazA.Seroprevalence of transfusion transmitted infections among different blood group donorsat Blood Bank LUMHS, Hyderabad. Pak J Med Sci. 2017; 33(2):443-446.

11. Motayo BO, Faneye AO, Udo UA, Olusola BA, Ezeani I, Ogiogwa JI. Seroprevalence of transfusion transmissible infections (TTI), in first time blood donors in Abeokuta, Nigeria. A fr Health Sci. 2015;15(1):19-24.doi: 10.4314/ahs.v15i1.3.

12.Ji ZH, Li CY, Lv YG, Cao W, Chen YZ, Chen XP, Tian M, Li JH, An QX, Shao ZJ. The prevalence and trends of transfusion-transmissible infectious pathogens among first-time, voluntary blood donors in Xi'an, China between 1999 and 2009. Int J Infect Dis. 2013; 17(4):e259-62. doi: 10.1016/j.ijid.2012.10.006.

13.Al-Bahrani A, Panhotra BR. Prevalence of HBsAg and anti $\mathrm{HCV}$ antibodies in blood donors of the Al-Hasa region of the Saudi Arabia. Ann Saudi Med. 2001; 21(34):234-235

14.Saghir, FM Al-Hassan et al. Frequencies of HBV, HCV, HIV, and Syphilis Markers Among Blood Donors. Trop J Pharm Res, February2012; 11 (1): 135.

15.Chaudhary I A, Khan S S, Masood R, Sardar M A, Mallhi A A. Seroprevalence of Hepatitis B and C among the healthy blood donors at Fauji Foundation Hospital, Rawalpindi. Pak J Med Sci. 2007; 23(1): 64-67.

16.Alizadeh AH, Ranjbar M, Ansari S, MirArab A, Alavian SM, Mohammad K, Hekmat L. Seroprevalence of hepatitis B in Nahavand, Islamic Republic of Iran. East Mediterr Health J.2006; 12(5):528-537. 
17.Noordeen, F., Pitchai, F.N.N. and Rafeek, R.A., 2015. A Review of Hepatitis B Virus Infection in Sri Lanka. Sri Lankan Journal of Infectious Diseases, 5(2), pp.42-50. DOI: http://doi.org/10.4038/sljid.v5i2.8087.

18.El-Hazmi MM. Prevalence of HBV, HCV, HIV-1,2 and HTLV-I/II infections among blood donors. Saudi Med J 2004; 25(1) 26-33.

19.Ahmad N, Asgher M, Shafique M, Qureshi JA. An evidence of high prevalence of Hepatitis $\mathrm{C}$ virus in Faisalabad, Pakistan. Saudi Med J. 2007;28(3):390-395.

20.Maan MA, Hussain F, Jamil M. Epidemiology of hepatitis $\mathrm{C}$ viral infection in Faisalabad, Pakistan: a retrospective study (2010-2012).Afr Health Sci. 2014;14(4):810-5. doi: 10.4314/ahs.v14i4.6.

21.Arshad A, Ashfaq UA. Epidemiology of Hepatitis C Infection in Pakistan: Current Estimate and Major Risk Factors. Crit Rev Eukaryot Gene Expr.2017; 27(1):6377.

22. Salawu L, Bolarinwa RA, Adegunloye AB, MurainaHA. HBsAg, anti-HCV, anti-HIV, and VDRL in blood donors: Prevalence and trends in the last three and a half years in a tertiary health mcare facility in IleIfe,Nigeria. Inter. J. Med. Med. Sci. 2010; 2: 335-341

23.Manzoor I, Hashmi NO, Daud SE, Ajmal SA, Fatima HI, Rasheed ZA, Syed SA. Seroprevalence of transfusion transmissible infections (TTIS) in blood donors. Biomedica. 2009; 25(10):154-8.

24.Ejele OA, Erhabor O, Nwauche CA.The risk of transfusion-transmissible viral infections in the NigerDelta area of Nigeria. Sahel Medical Journal 2005; 8:1619.

25.Bhawani Y, Rao PR, Sudhakar V. Seroprevalence of transfusion transmissible infections among blood donors in a tertiary care hospital of Andhra Pradesh. Biol Med. 2010;2(4):45-8.

26. Waheed U, Khan H, Satti HS, Ansari MA, Malik MA, Zaheer HA. Prevalence of transfusion transmitted infections among blood donors of a teaching hospital in Islamabad. Ann Pak Inst Med Sci. 2012;8(4):236-9.

\section{Author`s Contribution}

Dr. Sarwat Jahan: Study design, data collection, Interpretation of results, manuscript writing

Dr. Saira Mushtaq: Statistical analysis, interpretation of results, formulation of tables, writing the manuscript. Reviewed and approved the manuscript.

Dr. Farah Amir Ali: Acquisition of data, interpretation of results, editing and formatting the manuscript. Reviewed and approved the manuscript. 